\title{
Mass mortality of Nile tilapia caused by co-infection with Enterogyrus spp. (Monogenea: Ancyrocephalinae) and Aeromonas jandaei following transport stress
}

\author{
Inácio Mateus Assane ${ }^{1}$, Karen Dayana Prada-Mejia ${ }^{1}$, Sílvia Umeda Gallani², Natasha \\ Fernandes Weiser $^{1}$, Gustavo Moraes Ramos Valladão ${ }^{2}$, and Fabiana Pilarski ${ }^{1}$ \\ ${ }^{1}$ UNESP \\ ${ }^{2}$ Nilton Lins University
}

April 14, 2021

\begin{abstract}
Monogenean infection of the internal organs is extremely rare when compared to external infections. This study describes mass mortality of Nile tilapia (Oreochromis niloticus L.) originating from co-infection with Enterogyrus spp. and Aeromonas jandaei following transport stress. The first fish deaths occurred on day 1 post-transport, while cumulative mortality reached approximately $90 \%$ by day 10 post-stocking. An atypical amount of pale (whitish) faeces floating on the surface of the water as well as typical clinical signs of motile Aeromonas septicemia, were reported. Adult monogeneans and countless eggs of monogeneans were found in the stomachs and the intestines of both moribund and dead fish, respectively. Two strains of $A$. jandaei were isolated from the kidneys. Scanning electron microscope microphotographs of the stomach revealed the presence of numerous monogeneans penetrating deep into the gastric tissue, and diffuse lesions filled with bacilliform bacteria. This is the first report of co-infection by Enterogyrus spp. and A. jandaei in Nile tilapia and the first report of E. coronatus, E. foratus, and E. malbergi parasitizing tilapia in Brazil. These findings indicate that synergic co-infection by Monogenean stomach parasites (E. coronatus, E. foratus, and E. malbergi) and A. jandaei may induce high mortalities in tilapia following transport stress.
\end{abstract}

Mass mortality of Nile tilapia caused by co-infection withEnterogyrus spp. (Monogenea: Ancyrocephalinae) and Aeromonas jandaei following transport stress

Short running title: Natural co-infection in Nile tilapia

Inácio Mateus Assane ${ }^{1,2}$, Karen Dayana Prada-Mejia ${ }^{1}$, Sílvia Umeda Gallani ${ }^{3}$, Natasha Fernandes Weiser ${ }^{1}$, Gustavo Moraes Ramos Valladão ${ }^{3}$, and Fabiana Pilarski ${ }^{1,4^{*}}$

${ }^{1}$ Post-graduate program in Aquaculture, Laboratory of Microbiology and Parasitology of Aquatic Organisms, São Paulo State University (Unesp), Aquaculture Center of Unesp, Jaboticabal, SP, Brazil, 14884.900.

${ }^{2}$ Universidade Zambeze (UniZambeze), Faculdade de Ciências Agrárias, Ulónguè, Tete, Mozambique, 0713-02

${ }^{3}$ Postgraduate Program in Aquaculture, Nilton Lins University, Manaus, AM, Brazil, 69058- 030.

${ }^{4}$ Graduate Program in Agricultural and Livestock Microbiology, Laboratory of Microbiology and Parasitology of Aquatic Organisms, São Paulo State University (UNESP), School of Agricultural and Veterinarian Sciences, Jaboticabal, SP, Brazil, 14870.000

*Corresponding author at: fabiana.pilarski@unesp.br, +55 16 3209-8137

\section{Summary}


Monogenean infection of the internal organs is extremely rare when compared to external infections. This study describes mass mortality of Nile tilapia (Oreochromis niloticus L.) originating from co-infection with Enterogyrus spp. and Aeromonas jandaeifollowing transport stress. The first fish deaths occurred on day 1 post-transport, while cumulative mortality reached approximately $90 \%$ by day 10 post-stocking. An atypical amount of pale (whitish) faeces floating on the surface of the water as well as typical clinical signs of motile Aeromonas septicemia, were reported. Adult monogeneans and countless eggs of monogeneans were found in the stomachs and the intestines of both moribund and dead fish, respectively. Two strains of $A$. jandaei were isolated from the kidneys. Scanning electron microscope microphotographs of the stomach revealed the presence of numerous monogeneans penetrating deep into the gastric tissue, and diffuse lesions filled with bacilliform bacteria. This is the first report of co-infection by Enterogyrus spp. and A. jandaeiin Nile tilapia and the first report of E. coronatus, E. foratus, and E. malbergi parasitizing tilapia in Brazil. These findings indicate that synergic co-infection by Monogenean stomach parasites (E. coronatus , E. foratus , and E. malbergi ) and A. jandaei may induce high mortalities in tilapia following transport stress.

Keywords : Nile tilapia, mass mortality, co-infection,Enterogyrus spp., Aeromonas jandaei, transport stress.

\section{Introduction}

Nile tilapia (Oreochromis niloticus L.) is the third most-produced species in world aquaculture (FAO, 2020) and the main cultured fish in many countries. Since 2002, Nile tilapia has been the main fish cultured in Brazil and, in 2019, its production was estimated at 323,700 tons (61.1\% of Brazilian aquaculture production) (IBGE, 2019). Regardless of their tolerance to multiple stress-causing agents, conditions inherent to intensive fish farming systems predispose fish to disease outbreaks.

Disease outbreaks are considered one of the main obstacles for aquaculture development, leading to major concerns regarding massive economic losses. Brazilian aquaculture is a billion-dollar industry, with production relying on small farms, thus making health status a central issue in the intensification of production systems, particularly for those concerning Nile tilapia (Valenti et al., 2021). In Brazil, the eighth largest inland major producer of finfish in the world, Tavares-dias \& Martins (2017) estimated the annual loss of finfish production due to parasitic and infectious diseases to be $15 \%$ (about USD 84 million).

Nile tilapia is commonly affected by bacterial infections caused by Aeromonas spp. (Dong et al., 2017; Raj et al., 2019),Streptococcus spp. (Chideroli et al., 2017; Niu et al., 2020),Flavobacterium columnare (Dong et al., 2015), Edwardsiellaspp. (Oh et al., 2020), Francisella noatunensis subsp.orientalis (Sebastião et al., 2017), Lactococcus garvieae(Evans et al., 2009), and Vibrio vulnificus (Sumithra et al., 2019), as well as parasitic diseases caused mainly by protozoans (Martins et al., 2015; Rodrigues et al., 2019), monogenetic (Abdel-Latif and Khafaga, 2020) and digenetic trematodes (Abdel-Latif et al., 2020). Co-infection by these pathogens, either simultaneously or as a secondary concurrent infection, potentiates the pathogenic effects and leads to serious negative consequences for the host (Abdel-Latif et al., 2020).

Motile Aeromonas septicaemia (MAS), also known as aeromoniosis, is probably the most important bacterial disease concerning aquaculture in tropical regions. The role of Aeromonas as a primary or secondary pathogen of fish is already known (Austin and Austin, 2016; Rasmussen-Ivey et al., 2016; Hoai et al., 2019; ProiettiJunior et al., 2021). However, among the 14 taxa known to be pathogenic to fish, only A. hydrophila and $A$. veronii are commonly linked with mass mortality in Nile tilapia in most countries (Janda and Abbott, 2010; Sudheesh et al., 2012; Hassan et al., 2017; Delphino et al., 2019). Thus, there is little information about A. jandaei as a causative agent of disease in Nile tilapia, despite it being capable of causing mass mortality (Dong et al., 2017) and negative impacts on the development of aquaculture.

The Monogenea are among the main parasites affecting aquaculture worldwide. Monogenea are generally considered ectoparasites since they mainly affect gills and the external surface of fish (Kearn, 2011), however, this large group is also composed of endoparasites that affect the aquatic organisms' internal organs, such as the urinary tract (Kohn, 1990; Cepeda et al., 2011), stomach (Pariselle et al., 1991; Bilong-Bilong et al., 1996; Jeronimo et al., 2010; Luus-Powell et al., 2020), and intestine (Paperna, 1963). 
Enterogyrus is a genus of monogenean parasites that inhabit the digestive system (stomach and anterior intestinal lumen) of many fish species. Although Enterogyrus is commonly found parasitizing African and Asian cichlids (Vanhove et al., 2016), reports concerning its parasitism, host-pathogen relationship, and geographical distribution are scarce. There are currently 12 species ofEnterogyrus described as parasites of fish from Africa and Asia; especially, from Africa: E. cichlidarum (Paperna, 1963); E. amieti ; E. crassus (Bilong-Bilong et al., 1996); E. barombiensis (Bilong Bilong et al., 1991); E. coronatus ;E. foratus (Pariselle et al., 1991); E. malmbergi (Bilong Bilong et al., 1988); E. melenensis (Bilong-Bilong et al., 1989);E. multispiralis and E. mashegoi (Luus-Powell et al., 2020), and from Asia: E. globodiscus , and E. papernai(Gussev and Fernando, 1973).

To our knowledge, in the Americas, previous reports include onlyE. malmbergi infecting Oreochromis aureus and O. mossambicus x Oreochromis spp. in Cuba (Leon et al., 2012);E. malmbergi infecting Thorichthys callolepis, Vieja fenestrata, and O. niloticus in Mexico (Jimenez-Garcia et al., 2001); and E. cichlidarum infecting O. mossambicus and O. niloticus in the USA (Noga and Flowers, 1995) and Brazil (Jeronimo et al., 2010), respectively. All these reports involve exotic African fish, while high mortality rates (40\% or greater) were reported only by Noga and Flowers (1995).

Over the last decade, the number of studies on synergistic co-infections between parasites and bacteria in Nile tilapia has grown (Abdel-Latif et al., 2020). However, most reposts are concern parasitism by ectoparasites, such as Ichthyophthirius multifiliis ,Trichodina spp., Gyrodactylus spp., andDactylogyrus spp., and bacteria, such as A. hydrophila, F. columnare, Streptococcus iniae, V. alginolyticus, and V. harveyi (Nofal and Abdel-Latif, 2017; Abdel-Latif and Khafaga, 2020; Abdel-Latif et al., 2020). Currently, there is no information available concerning co-infection byEnterogyrus and A. jandaei in fish. Most studies onEnterogyrus parasitism focus on taxonomic aspects (Zhang et al., 2019; Luus-Powell et al., 2020), while few reports indicate that $A$. jandaei is pathogenic to aquaculture fish (Dong et al., 2017; Proietti-Junior et al., 2021). In this study, we report on the mass mortality of Nile tilapia caused by co-infection with Enterogyrusspp. (Monogenea: Ancyrocephalinae) and A. jandaei following transport stress.

\section{Materials and methods}

\section{Fish and clinical history}

A batch of apparently healthy Nile tilapia (O. niloticus L.) fingerlings were obtained from a commercial fish farm in Sales Oliveira, State of Sao Paulo, Brazil. Fish were reared for three months in an earth pond in the Aquaculture Center of Sao Paulo State University (Caunesp, Jaboticabal) and then, transferred to experimental fibreglass tanks $(500 \mathrm{~L})$. The first fish death occurred on the day following their transportation; within 3 days of transportation, the mortality rate reached $45.4 \%$ while, on day 10 , the cumulative mortality rate reached approximately $90 \%$. All clinical signs of disease were recorded and samples were collected for parasitological and microbiological analysis.

Water physicochemical parameters were appropriate for Nile tilapia maintenance, both in the earthen pond and the fibreglass tanks.

\section{Parasitological analysis}

The parasitological analysis was performed following routine parasitological procedures for parasite identification. Briefly, fish were euthanized through brain concussion and spinal cord section, as recommended by the Federal Council of Veterinary Medicine (CFMV). Then, samples from the gills, body mucus, stomach, and intestine were individually collected through scraping with the aid of glass slides and then viewed under light microscopy (using a magnifying glass and optical microscope). Stomach and intestine content were also viewed under light microscopy.

\section{Parasite identification}

After routine parasitological analysis, the stomach of five fish were collected in formaldehyde at a dilution of 1:4000 in order to identify the parasites. After $24 \mathrm{~h}$, the tissue was scraped to release the parasite specimens in 
$10 \%$ formalin, maintaining the samples in $5 \%$ formalin $(1: 1, \mathrm{v} / \mathrm{v})$ final solution. Monogenea were individually captured with a needle and deposited on glass slides containing a drop of Hoyer's medium to evaluate their sclerotized structures. The sclerotized structures were photographed (100x and 400x magnification) using a Nikon E200(r) photomicroscope equipped with a Moticam 2300(r) image capture system. Thereafter, the dimensions were processed using Image-Pro Plus 4.5 software.

The measured characters were: body length; body width; pharynx diameter (p); haptor (h) length; haptor width; dorsal (da) and ventral (va) anchor total length (a), blade length (b), shaft length (c), guard length (d), and point length (e); ventral bar (vb) length and width; penis (pe) total curved length and base maximum width; and marginal hooks $(\mathrm{mh})$ length I-VII. The morphometric measures were obtained following the recommendations of Gussev (1962) and Pariselle et al. (1991), while the terminology is according to Pariselle and Euzet (2009). All parasite measurements (in micrometres) were presented as arithmetic mean +- standard deviation (minimum-maximum).

\section{Microbiological analysis}

The microbiological analysis was performed following routine microbiological procedures for bacterial isolation and identification. Samples were taken from the kidneys and brain under aseptic conditions and inoculated on Brain Heart Infusion broth (BHIB, KASVI ${ }^{(\mathrm{r})}$ ) prior to being incubated at $28 \mathrm{oC}$ for 24 and 48 h. A loop full of bacterial culture was streaked onto Brain Heart Infusion agar with sheep blood (BHIASB, $\mathrm{KASVI}^{(\mathrm{r})}$ ) and incubated at $28 \mathrm{oC}$ for 24 and $48 \mathrm{~h}$. Purified isolates were labelled (Strain ID and date of collection) and used as stocks for further studies. Stocks were made with $15 \%$ glycerol and kept at -80deg C until use. Pure colonies were identified by morphological, biochemical, and molecular tests.

\section{Bacterial identification}

Colony morphology and the arrangement of each isolate were described after 24 and $48 \mathrm{~h}$ of incubation at 28 oC. Bacterial films were prepared from each 24 and $48 \mathrm{~h}$ pure culture of purified isolate and stained with Gram stain before being examined under an optical microscope $(1000 \mathrm{x})$ to describe the bacterial shape and cell arrangements.

Genomic DNA was extracted from the bacteria of freshly grown culture plates using a DNeasy blood and tissue kit (Qiagen, Germany) following the manufacturer's instructions (Qiagen, 2020). The extracted DNA was quantified using a NanoDrop ${ }^{\mathrm{TM}} \mathrm{One} / \mathrm{One}^{\mathrm{C}}$ Microvolume UV-Vis Spectrophotometer (ThermoFisher Scientific $^{\mathrm{TM}}$, Brazil) and then utilised in performing polymerase chain reaction (PCR) to amplify the $16 \mathrm{~S}$ rRNA, gyr $B$, and $r p o B$ genes. $16 \mathrm{~S}$ rRNA was amplified using the primers and PCR conditions described by Sebastiao et al. (2015). For the PCR involving gyrB and rpoB , Invitrogen Platinum IITaq Hot-Start DNA Polymerase (Lot 00813145) and $10 \mathrm{mM}$ dNTP Mix (Lot 1987090) were used following the manufacturer's recommendations. The primers described by Yanez et al. (2003) and Korczak et al. (2004) were used for the gyrB and $r p o B$ PCRs, respectively.

The amplicons were sequenced using the BigDye Terminator v3.1 Cycle Sequencing Kit (Applied Biosystems) in the ABI 3730 XL DNA Analyser (Applied Biosystems). Sequences were visualized, assembled, and edited using BioEdit (BioEdit version 7.0.0; Hall, 1999) and FinchTV (Geospiza) software (Gallagher and Wiley, 2008).

Gene sequences were identified using the Basic Local Alignment Search Tool (BLAST) (https://blast.ncbi.nlm.nih.gov/Blast.cgi). Nucleotide sequence identity [?]98\% was used as the criterion for identification. Raw sequences of $\operatorname{gyr} B$ and $r p o B$ genes were translated to protein to confirm the absence of stop codons in the middle of the sequence. Gene sequences were deposited in the NCBI GenBank database (www.ncbi.nlm.nih.gov/genbank).

\section{Phylogenetic analysis}

The 16S rRNA, gyrB, and rpoB gene sequences of clinical isolates (11), environmental (3), and reference strains (14) ofAeromonas, isolated in different locations (Brazil, China, India, and The United States of 
America), as well as the reference strains of two related organisms, Plesiomonas shigelloides NCTC10360 (Enterobacterales) and $V$. anguillarum NCTC12159 (Vibrionales), were obtained from the NCBI GenBank Database, aligned with the sequences from this study using MAFFT (Katoh et al., 2019), and used for phylogenetic analysis.

Sequences were concatenated using Geneious 5.6.3 (Drummond et al., 2012) and used for phylogenetic reconstruction by Maximum Likelihood (ML, 10,000 replicates) and Bayesian Inference (BI) methods, using MEGA version X (Kumar et al., 2018) and MrBayes 3.2.2 (Ronquist and Huelsenbeck, 2003), respectively. The best evolutionary model for ML (16s rRNA: K2 + G + I; gyrB : T92+G; rpoB : K2 + G) and BI (16s rRNA: HKY + I; gyrB : SYM + G; rpoB : TIM2ef + G) was selected based on the Bayesian Information Criterion (BIC) and the Akaike Information Criterion (AIC), estimated in MEGA version X and jModelTest 2.1.0 (Darriba et al., 2012), respectively.

For multilocus sequence analysis, the best-fit partitioning schemes and models of evolution for nucleotides were selected based on PartitionFinder2 on XSEDE (Guindon et al., 2010; Lanfear et al., 2016).P. shigelloides and $V$. anguillarum were used as outgroups, and only support values (ML bootstrap and BI posterior probabilities) greater than or equal to $70 \%$ (bootstrap) and $0.70(\mathrm{PP})$ were represented in the phylogenetic tree.

\section{Histopathology}

Immediately after euthanasia, the stomachs $(\mathrm{n}=4)$ of infected fish were collected and fixed in buffered formalin (10\%). After $24 \mathrm{~h}$, the tissue was transferred to $70 \%$ alcohol and processed following usual histological techniques in paraffin embedding. Histological sections $(5 \mu \mathrm{m})$ were stained with hematoxylin/eosin (H\&E) and Sudan. The alterations were analyzed under optical microscopy (Nikon E200ß) equipped with a Motic 5.0 image capture system.

\section{Scanning electron microscopy (SEM)}

Two moribund fish were euthanized for stomach sampling. Samples were fixed with $2.5 \%$ glutaraldehyde and post-fixed in $1 \%$ osmium tetroxide, both with sodium cacodylate buffer. Subsequently, the samples were dehydrated in serial concentrations of alcohol at 30\%, $70 \%, 80 \%, 90 \%$, and $100 \%$. The samples were criticalpoint dried and then mounted on aluminium stubs and gold-coated. The villi surface was analyzed, focusing on the description of the parasite/stomach tissue relationship, and photographed using a ZEISS EVO 10 scanning electron microscope (ZEISS, Germany) at $15.00 \mathrm{kV}$ electron high tension (EHT).

\section{Antimicrobial therapy}

During the outbreak, 20 fish exhibiting clinical signs of motile Aeromonas septicemia were separated into two groups of 10 fish each (G1 and G2) and administered either $10 \mathrm{mg} / \mathrm{kg}$ body weight (bw) florfenicol (FFC) (G1) or $10 \mathrm{mg} / \mathrm{kg}$ bw thiamphenicol (TAP) (G2) via gavage. Unmedicated fish were used as a control group (G0). Fish were observed for 10 days and clinical signs of infection were recorded.

\section{Results}

\section{Clinical signs}

Fish death first occurred on the day following their transportation and the tanks in which the fish were kept displayed an atypical amount of pale (whitish) faeces floating around. Three days post-transportation the mortality rate reached $45.4 \%$ while, 10 days post-transportation, the cumulative mortality rate reached approximately $90 \%$. Clinical signs of motile Aeromonas septicemia, including lethargy, inappetence, surface swimming, exophthalmia, cloudy eyes, haemorrhagic patches and redness of the skin, below the opercula and at the base of all fins, fin rot, and pale body surface were observed (Figure 1).

\section{Parasitological identification}

No significant parasitic infection was identified in samples from the gills or body mucus. Adult monogeneans were found in the stomach of Nile tilapia (O. niloticus L.), while countless monogenean eggs were found 
in the intestines (Figure 2). All specimens found infecting the stomach belonged to the genus Enterogyrus Paperna, 1963.Enterogyrus malmbergi Bilong Bilong, 1988 (Figure 3E, and 4B) was the most abundant.

E. malmbergi showed a robust and wide body, with a short male organ and a large pharynx, when compared to other species found in the present study (Table 1). The haptor has a slight constriction that divides it from the rest of the body, and it is armed with two pairs of anchors. The dorsal anchor has a lower axis-blade ratio, while the ventral anchor has the same pattern as the dorsal but of smaller size. The ventral bar is compact and has marked sclerotization, slightly straight, with wider ends and a slight hollow in the middle, with a serrated appearance. Seven pairs of identical hooks were observed in the haptor. The penis is positioned in the anterior quarter, with a spiral pattern represented by the formula: 3-2-1 / 3-1-2, and a prominent spiral standing out on the last lap, in all specimens. The pharynx is muscular while, before it, there are two pairs of ocular points (Figure 3).

The other species found was E. coronatus Pariselle, Lambert \& Euzet, 1991 (Figure 3A, and 4C), which has a smaller body size/thickness, and smaller hook structures and pharynx but, on the other hand, presents a male organ almost $50 \%$ larger than E. malmbergi (Table 1). Its prominent dense integument is striated transversely and differentiated from the haptor integument, which is thin and has no streaks. E. coronatus has two pairs of eyespots, with the anterior pair smaller and more spaced than the posterior pair, and in some specimens close or fused. The pharynx is spherical and posterior to the eyespots (Figure 3). The anatomy of the genital complex is similar to that of other species of the genus Enterogyrus ; being that the penis (spiral pattern: 5-2-1 + 3) is located medially in the anterior portion of the body. The shape of the haptor is variable between specimens (tongue or glass) and is delimited from the body by a slight constriction. The haptor consists of two pairs of anchors, the ventral anchors being smaller than the dorsal ones. The ventral bar is thin and tenuous (fragile) in the shape of a ' $V$ '. The marginal hooks are robust, except for the first and second pairs (which are thinner), and have a similar shape. In the dorsal anchor, the blade was longer than the axis.

Only one E. foratus -like specimen was observed in the stomachs (Figure 4A) of the diseased fish; the specimen was only detected through SEM and, thus, no internal characteristics were reported. The specimen had a haptor comprised of two segments and strangulation between the body and the haptor. More details about the morphology of the E. foratus -like specimen found in this study are presented in Figure 4.

\section{Scanning electron microscopy}

In the photomicrographs, it was possible to observe the presence of numerous monogeneans (Enterogyrus spp.) penetrating deep into the gastric tissue (Figure 2A). Diffuse lesions were also noted, revealing the marks caused by the attachment of the hooks (Figure 2D-G). Within these lesions, it was possible to observe the presence of rod-shaped bacteria (Figure $2 \mathrm{D}-\mathrm{G}$ ).

\section{Bacterial identification}

Two strains (IA17 and GV1) of motile rod-shaped Gram-negative bacteria, 0.3 to $0.9 \mu \mathrm{m}$ in diameter and 0.6 to $3.3 \mu \mathrm{m}$ in length, were isolated from the kidneys of Nile tilapia exhibiting typical clinical signs of motile Aeromonas septicemia.

Blast results indicated that the $16 \mathrm{~S}$ rRNA, gyrB , and rpoBfragments of the clinical isolate IA17 (874, 555 and $453 \mathrm{bp}$ ) were $99.66 \%, 95.14 \%$, and $99.78 \%$ identical to the $A$. jandaeireference strain ATCC 49568 (GenBank accession no. NR_119040, AJ868391 and AY851121), respectively. The 16S rRNA (409), gyrB (444), andrpoB (465) fragments of GV1 clinical isolate were $100 \%, 97.03 \%$, and $98.87 \%$ identical to the reference strain A. jandaei ATCC 49568 (GenBank accession no. NR_119040, AJ868391 and AY851121), respectively.

IA17 and GV1 clustered together and were placed on the same clade of the reference strain A. jandaei ATCC 49568 and the pathogenic $A$. jandaei B29 (GenBank accession no. JQ040105) (Figure 5). As shown in Figure 5 , all strains of $A$. jandaei were placed in the same clade and were different from other Aeromonas. Species multilocus phylogenetic analysis clustering showed that the concatenated tree was highly robust, as indicated 
by the high support values (Maximum Likelihood bootstrap and Bayesian Inference posterior probabilities) found in the tight-clades (Figure 5).

Based on their morphological, biochemical, and molecular characteristics, IA17 and GV1 were identified as $A$. jandaei. Gene sequences were deposited in the NCBI GenBank database (www.ncbi.nlm.nih.gov/genbank) under accession nos. MT937283 (IA17 16s rRNA fragment), MT796424 (IA17gyrB fragment), MT735587 (IA17 rроB fragment), MH155229 (GV1 16s rRNA fragment), MT796425 (GV1 gyrB fragment), and MT904882 (GV1 rpoB fragment).

\section{Histopathology}

The presence of Monogenea in the fish stomachs resulted in ulcers in the mucosal layer at the sites of parasite attachment (Figure 6).

\section{Treatment and control of disease}

The typical clinical signs of the disease started to disappear 3 days post-medication with a single oral dose of antibiotic while, at day 10 post-medication, all medicated fish (G1 and G2) were healthy. There was no record of mortality in the G1 and G2 groups. On the other hand, at day 10 post-medication, high rates of morbidity and mortality (approximately 90\%) were observed in the unmedicated group (G0). Both florfenicol $(10 \mathrm{mg} / \mathrm{kg} \mathrm{bw})$ and thiamphenicol $(10 \mathrm{mg} / \mathrm{kg} \mathrm{bw})$ were effective against $A$. jandaei.

\section{Discussion}

Cases of monogenean infection in internal organs are neglected and extremely rare when compared to Monogenea external infections. Moreover, in most cases, the infected fish are not farmed fish and low rates of morbidity and mortality are reported (Jerônimo et al., 2010; Madanire-Moyo and Avenant-Oldewage, 2014, 2015; Zhang et al., 2019; Luus-Powell et al., 2020). The most recent report regarding a high rate of morbidity and mortality in farmed fish originating from a monogenean internal infection is from 1995, occurring in the USA (Noga and Flowers, 1995). Here, the natural co-infection of Nile tilapia (O. niloticus L.), with three species of Monogenea found parasitising the stomach along with A. jandaei is reported following transport stress. High rates of morbidity and mortality were observed during the disease outbreak.

All of the endoparasite specimens identified in this study are from the genus Enterogyrus Paperna, 1963. The morphology of $E$. foratus -like specimens described here is similar to that of E. foratus described by Pariselle et al., (1991). The measurements and morphologies of taxonomic characteristics of E. coronatus and $E$. malmbergi from this study are similar to those of E. coronatus and E. malmbergi described by Pariselle et al. (1991) and León et al. (2012), respectively. However, our specimens had a smaller body size (all species); an enlarged bar with a serrated aspect in the entire amplitude (E. malmbergi ) (Madanire-moyo and Avenantoldewage, 2014; Zhang et al., 2019); in the dorsal anchor (ofE. coronatus), the blade was longer than the axis, and the penis exhibited a spiral pattern: $5-2-1+3$ (E. coronatus $)$. These differences are probably due to either difference in the host and environmental conditions, which highly influence Monogenea embryogenesis and development (Dmitrieva and Dimitrov, 2002), or differences in parasite processing techniques (fixation and assembly), that significantly alter specimen morphology (Fankoua et al., 2017).

The microbiological analyses of diseased fish indicated that they were also infected by $A$. jandaei. The clinical history of the outbreak described in this study is very similar to the $A$. jandaeioutbreak recently described by Dong et al. (2017) in Nile tilapia from Thailand. However, no parasitism and clinical signs of parasitism were reported by Dong et al. (2017). The use of molecular approaches, such as $16 \mathrm{~S}$ rRNA, gyrB , and rpoB gene sequencing, as well as multilocus phylogenetic analysis, allowed us to identify the clinical isolates as $A$. jandaei and clarify their phylogenetic relationships with other Aeromonas spp..

A. jandaei seems to be an opportunistic pathogen with a cosmopolitan distribution, similar to A. hydrophila (Harikrishnan and Balasundaram, 2005; Dong et al., 2017). According to Pakingking et al. (2020), Aeromonas spp. constitute a part of the normal microbiota of healthy tilapia and their production environment, and their density can vary from $10^{1}$ to $10^{3} \mathrm{CFU} / \mathrm{mL}$ in the culture environment, $10^{2}$ to $10^{5} \mathrm{CFU} / \mathrm{mL}$ in the 
intestines, and $10^{4}$ to $10^{7} \mathrm{CFU} / \mathrm{mL}$ in the gills. Thus, we believe that, along with the transport stress, parasitism byEnterogyrus may have strongly contributed to the A. jandaei outbreak. Moreover, diseased fish medicated with a single oral dose of antimicrobials known to be effective against Aeromonas (florfenicol and thiamphenicol) (Assane et al., 2019) recovered, suggesting that the main pathogen was sensitive to these antimicrobials.

One of the main constraints to the aquaculture of farmed fish is their vulnerability to disease, which leads to high rates of morbidity and mortality. Although the histopathology showed that parasitism was not the main cause of fish mortality, the presence of Monogenea in the fish stomachs was sufficient and essential to cause ulcers in the mucosal layer at sites of parasite attachment. Therefore, parasitism was not sufficient to incite a direct inflammatory response or other disturbance. Indeed, most fish parasites require the host to be alive for survival and, in cases of low to mild parasitism, the impacts on host health, such as ascertained in this study, are mainly attributed to secondary pathogens, especially those of bacterial origin. In this report, we associate $A$. jandaei as the secondary pathogen and the most probable cause of host death to septicemia. Thus, co-infection commonly arises when two or more pathogens infect the same host, either as a simultaneous infection or as a secondary concurrent infection, and the pathogenic effects of $A$. jandaei can lead to serious negative consequences on Nile tilapia (Abdel-Latif et al., 2020).

The SEM analysis revealed diffuse lesions associated with the presence of bacteria, highlighting an important aspect of infection byEnterogyrus spp., which corroborates with secondary infection by motile Aeromonas septicemia (MAS). Although several bacteria will not develop in the conditions provided by the stomach, the occurrence of diffuse lesions allows microorganisms to access the bloodstream quickly, thus resulting in systemic infection in immunosuppressed fish.

Previous studies have reported the occurrence of natural co-infection by two or more homologous pathogens in Nile tilapia, including bacterial co-infections; parasitic co-infections; parasitic and bacterial co-infections; bacterial and viral co-infections; fungal and bacterial co-infections; and viral, bacterial, and parasitic coinfections (Abdel-Latif et al., 2020). Nevertheless, to our knowledge, this is the first report of natural endoparasitic and bacterial co-infection byEnterogyrus spp. and A. jandaei, and the first report of E. coronatus , E. foratus -like, and E. malbergiparasitizing Nile tilapia in Brazil.

Although diseased fish showed some signs that can facilitate the beginning of the parasitological diagnosis, such as the presence of transparent or whitish faeces and an atypical amount of faeces floating on the surface of the water, parasitism by Enterogyrus can be considered silent in the culture environment. This is due to the fact that signs of parasitism are masked in an earthen pond, where the visualization of animals and faeces is not easy; meanwhile, in cages, the faeces are taken out of the environment quickly. Therefore, it is necessary to remain alert for any unusual accumulation of faeces with such characteristics in the water flower or stuck to the grids of the cage.

Another factor compromising knowledge regarding monogenean endoparasites is the lack of microscopic analyses of internal organs, mainly the stomach and urinary bladder, which are the main organs affected by monogenean endoparasites. Proper diagnosis depends on the correct selection of the most appropriate exams. Usually, parasitosis is diagnosed through microscopic analyses of the gill and mucus scrap content. Recently, Jesus et al. (2018) highlighted other key tools that have been neglected for an accurate diagnosis of parasitosis in tilapia. In this study, we encourage the inclusion of a microscopic analysis of the content of the internal organs during routine parasitic diagnosis for the identification of silent and emerging endoparasites in aquaculture.

In this study, in order to improve control strategies to protect Nile tilapia when infected with multiple pathogens, we establish the first report of three new species of Enterogyrus parasitizing the stomach of Nile tilapia in Brazil and also highlight the importance of including internal organs in routine sanitary status monitoring, leading to a more consistent diagnosis and prevention of MAS co-infectious outbreaks.

\section{Acknowledgements}


The assistance provided by Dr. Fernando Jose Zara and Dr. Claudia Maria Toddanelli Fiorillo from the Laboratory of Electronic Microscopy of FCAV- Unesp during SEM analysis, and ADM Socil for providing fish feed are gratefully acknowledged. This study has been partially funded by the Coordenacao de Aperfeicoamento de Pessoal de Nivel Superior - Brazil (CAPES) - Finance Code 001, grant 2019/22775-0, Sao Paulo Research Fundation (FAPESP), and Conselho Nacional de Desenvolvimento Cientifico e Tecnologico - Brazil (CNPq) - grant 301508/2019.

\section{Conflict of Interest Statement}

The authors have no conflicts of interest to declare.

\section{Data Availability Statement}

The data that support the findings of this study are available from the corresponding author upon reasonable request.

\section{References}

Abdel-Latif, H.M.R., M.A.O. Dawood, S. Menanteau-Ledouble, and M. El-Matbouli, 2020: The nature and consequences of co-infections in tilapia: A review. J. Fish Dis. 43, 651-664, DOI: 10.1111/jfd.13164.

Abdel-Latif, H.M.R., and A.F. Khafaga, 2020: Natural co-infection of cultured Nile tilapia Oreochromis niloticus with Aeromonas hydrophila and Gyrodactylus cichlidarum experiencing high mortality during summer. Aquac. Res. 51 , 1880-1892, DOI: 10.1111/are.14538.

Assane, I.M., K.S. Gozi, G.M.R. Valladao, and F. Pilarski, 2019: Combination of antimicrobials as an approach to reduce their application in aquaculture: Emphasis on the use of thiamphenicol/florfenicol against Aeromonas hydrophila . Aquaculture 507 , 238-245, DOI: 10.1016/j.aquaculture.2019.04.021.

Austin, B., and D.A. Austin, 2016: Bacterial Fish Pathogens, Disease of Farmed and Wild FishSixth Edit. Springer International Publishing Switzerland.

Bilong-Bilong, C.F., E. Birgi, and A. Lambert, 1989: Enterogyrus melenensis sp. nov. (Monogenea, Ancyrocephalidae), a parasite of the stomach of Hemichromis fasciatus in southern Cameroon. Rev. Zool. Africaine 103, 99-105.

Bilong-Bilong, C.F., L. Euzet, and E. Birgi, 1996: Monogenean stomach parasites of cichlid fishes from Cameroon: Two new species of the genus Enterogyrus Paperna, 1963 (Ancyrocephalidae). Syst. Parasitol.34 , 37-42, DOI: 10.1007/BF01531208.

Bilong Bilong, C.F., E. Birgi, and L. Euzet, 1991: Enterogyrus barombiensis n. sp. (Monogenea, Ancyrocephalidae) parasite stomacal de trois cichlidae endemiques du lac du cratere Barombi Mbo (Cameroun). Ann. Parasitol. Hum. Comparee 66 , 105-108, DOI: 10.1051/parasite/1991663105.

Bilong Bilong, C.F., E. Birgi, and N. Le Brun, 1988: Enterogyrus malmbergi n. sp. (Monogenea Ancyrocephalidae) parasite de l'estomac du Cichlidae Tilapia nilotica Linne, 1757 au Sud-Cameroun. Vol. 5, pp. 51-58. In: Ann. la Fac. des Sci. Yaounde, Biol.

Cepeda, P.B., P.S. Ceccarelli, and J.L. Luque, 2011: A new species of Kritskyia (Monogenea, Dactylogyridae) parasitic in the urinary bladder of Salminus brasiliensis (Characiformes) from the Pantanal wetlands, Brazil. Acta Parasitol. 56 , 270-273, DOI: 10.2478/s11686-011-0055-5.

Chideroli, R.T., N. Amoroso, R.M. Mainardi, S.A. Suphoronski, S.B. de Padua, A.F.A.A. Alfieri, A.F.A.A. Alfieri, M. Mosela, A.T.P. Moralez, A.G. de Oliveira, R. Zanolo, G.W. Di Santis, and U.P. Pereira, 2017: Emergence of a new multidrug-resistant and highly virulent serotype ofStreptococcus agalactiae in fish farms from Brazil.Aquaculture 479 , 45-51, DOI: 10.1016/j.aquaculture.2017.05.013.

Darriba, D., G.L. Taboada, R. Doallo, and D. Posada, 2012: JModelTest 2: More models, new heuristics and parallel computing. Nat. Methods 9 , 772, DOI: 10.1038/nmeth.2109. 
Delphino, M.K.V.C., C.A.G. Leal, I.A. Gardner, G.B.N. Assis, G.D. Roriz, F. Ferreira, H.C.P. Figueiredo, and V.S.P. Goncalves, 2019: Seasonal dynamics of bacterial pathogens of Nile tilapia farmed in a Brazilian reservoir. Aquaculture 498 , 100-108, DOI: 10.1016/j.aquaculture.2018.08.023.

Dmitrieva, E., and G. Dimitrov, 2002: Variability in the taxonomic characters of Black Sea gyrodactylids (Monogenea). Syst. Parasitol. 51 , 199-206, DOI: 10.1023/A:1014594614921.

Dong, H.T., V.V. Nguyen, H.D. Le, P. Sangsuriya, S. Jitrakorn, V. Saksmerprome, S. Senapin, and C. Rodkhum, 2015: Naturally concurrent infections of bacterial and viral pathogens in disease outbreaks in cultured Nile tilapia (Oreochromis niloticus ) farms.Aquaculture 448 , 427-435, DOI: 10.1016/j.aquaculture.2015.06.027.

Dong, H.T., C. Techatanakitarnan, P. Jindakittikul, A. Thaiprayoon, S. Taengphu, W. Charoensapsri, P. Khunrae, T. Rattanarojpong, and S. Senapin, 2017: Aeromonas jandaei and Aeromonas veroniicaused disease and mortality in Nile tilapia, Oreochromis niloticus (L.). J. Fish Dis. 40 , 1395-1403, DOI: $10.1111 /$ jfd.12617.

Drummond, A.J., B. Ashton, S. Buxton, M. Cheung, A. Cooper, C. Duran, J. Heled, M. Kearse, S. Markowitz, R. Moir, S. Stones-Havas, S. Sturrock, F. Swidan, T. Thierer, and A. Wilson, 2012: Geneious. .

Evans, J.J., P.H. Klesius, and C.A. Shoemaker, 2009: First isolation and characterization of Lactococcus garvieae from Brazilian Nile tilapia, Oreochromis niloticus (L.), and pintado,Pseudoplathystoma corruscans (Spix \& Agassiz). J. Fish Dis. 32 , 943-951, DOI: 10.1111/j.1365-2761.2009.01075.x.

Fankoua, S.O., A.R. Bitja Nyom, D. ne dort Bahanak, C.F. Bilong Bilong, and A. Pariselle, 2017: Influence of preservative and mounting media on the size and shape of monogenean sclerites. Parasitol. Res.116 , 2277-2281, DOI: 10.1007/s00436-017-5534-7.

FAO, 2020: The State of World Fisheries and Aquaculture 2020. Sustainability in Action. Rome: Food and Agriculture Organization of the United Nations.

Gallagher, S.R., and E.A. Wiley, 2008: Current Protocols Essential Laboratory Techniques. John Wiley \& Sons, Inc.

Guindon, S., J.F. Dufayard, V. Lefort, M. Anisimova, W. Hordijk, and O. Gascuel, 2010: New algorithms and methods to estimate maximum-likelihood phylogenies: Assessing the performance of PhyML 3.0. Syst. Biol.59 , 307-321, DOI: 10.1093/sysbio/syq010.

Gussev, A. V, 1962: Monogenoidea, In: Key to the Parasites of Freshwater Fish of the USSR. MoscowLeningrad: Publishing House House of Academy of Sciences of the USSR.

Gussev, A. V, and C.H. Fernando, 1973: Dactylogyridae (Monogenoidea) from the stomach of fishes. Folia Parasitol. (Praha).20, 207-212.

Hall, T., 1999: BioEdit: a user-friendly biological sequence alignment editor and analysis program for Windows 95/98/NT. pp. 95-98. In:Nucleic Acids Symp. Ser. Ibis Therapeutics.

Harikrishnan, R., and C. Balasundaram, 2005: Modern trends inAeromonas hydrophila disease management with fish. Rev. Fish. Sci. 13, 281-320, DOI: 10.1080/10641260500320845.

Hassan, M.A., E.A. Noureldin, M.A. Mahmoud, and N.A. Fita, 2017: Molecular identification and epizootiology of Aeromonas veroniiinfection among farmed Oreochromis niloticus in Eastern Province, KSA. Egypt. J. Aquat. Res. 43, 161-167, DOI: 10.1016/j.ejar.2017.06.001.

Hoai, T.D., T.T. Trang, N. Van Tuyen, N.T.H. Giang, and K. Van Van, 2019: Aeromonas veronii caused disease and mortality in channel catfish in Vietnam. Aquaculture 513, 734425, DOI: 10.1016/j.aquaculture.2019.734425. 
IBGE, 2019: Producao da Pecuaria Municipal 2019. Inst. Bras. Geogr. e Estatistica 47, 1-8, DOI: ISSN 0101-4234.

Janda, J.M., and S.L. Abbott, 2010: The genus Aeromonas: Taxonomy, pathogenicity, and infection. Clin. Microbiol. Rev. 23, 35-73, DOI: 10.1128/CMR.00039-09.

Jeronimo, G.T., G. Speck, M. Martins, G. Tomas Jeronimo, G. Speck, and M. Martins, 2010: First report of Enterogyrus cichlidarum paperna 1963 (Monogenoidea: Ancyrocephalidae) on Nile tilapia Oreochromis niloticus cultured in Brazil. Neotrop. Helminthol. 4, 75-80.

Jesus, R.B. de, S.U. Gallani, G.M.R. Valladao, G. Pala, T.F.A. da Silva, J.C. da Costa, S. Kotzent, and F. Pilarski, 2018: Trypanosomiasis causing mortality outbreak in Nile tilapia intensive farming: Identification and pathological evaluation. Aquaculture491 , 169-176, DOI: 10.1016/j.aquaculture.2018.02.002.

Jimenez-Garcia, M.I., V.M. Vidal-Martinez, and S. Lopez-Jimenez, 2001: Monogeneans in introduced and native cichlids in Mexico: evidence for fransfer. J. Parasitol. 87 , 907-909, DOI: 10.1645/0022$3395(2001) 087$.

Katoh, K., J. Rozewicki, and K.D. Yamada, 2019: MAFFT online service: Multiple sequence alignment, interactive sequence choice and visualization. Brief. Bioinform. 20, 1160-1166, DOI: 10.1093/bib/bbx108.

Kearn, G., 2011: Monogeneans the ultimate fish parasites.Biologist 58 , 29-32.

Kohn, A., 1990: Kritskyia moraveci n. g., n. sp. (Monogenea: Dactylogyridae) from the urinary bladder and ureters of Rhamdia quelen (Quoy \& Gaimard, 1824) (Pisces: Pimelodidae) in Brazil.Syst. Parasitol. 17 , 81-85, DOI: 10.1007/BF00009794.

Korczak, B., H. Christensen, S. Emler, J. Frey, and P. Kuhnert, 2004: Phylogeny of the family Pasteurellaceae based on rpoB sequences.Int. J. Syst. Evol. Microbiol. 54, 1393-1399, DOI: 10.1099/ijs.0.03043-0.

Kumar, S., G. Stecher, M. Li, C. Knyaz, and K. Tamura, 2018: MEGA X: Molecular evolutionary genetics analysis across computing platforms. Mol. Biol. Evol. 35 , 1547-1549, DOI: 10.1093/molbev/msy096.

Lanfear, R., P.B. Frandsen, A.M. Wright, T. Senfeld, and B. Calcott, 2016: Partitionfinder 2: New methods for selecting partitioned models of evolution for molecular and morphological phylogenetic analyses. Mol. Biol. Evol. 34, 772-773, DOI: 10.1093/molbev/msw260.

Leon, F.L.P., M.M. Perez, and R. Silveira, 2012: Primer reporte de monogeneos del genero Enterogyrus Paperna, 1963 (Monogenea: Ancyrocephalidae) en tilapias de cultivo en Cuba. Rev. Electron. Vet. 13, $1-12$.

Luus-Powell, W.J., G.N. Madanire-Moyo, M.M. Matla, and I. Přikrylová, 2020: Monogenean parasites from the stomach of Oreochromis mossambicus from South Africa: two new species of Enterogyrus (Dactylogyridae: Ancyrocephalinae). Parasitol. Res. 119 , 1505-1514, DOI: 10.1007/s00436-020-06650-2.

Madanire-moyo, G., and A. Avenant-oldewage, 2014: A new locality and host record for Enterogyrus coronatus ( Pariselle Lambert \& Euzet ( 1991 ) in South Africa and a review .... DOI: 10.2478/s11687-014-0203-1.

Madanire-Moyo, G.N., and A. Avenant-Oldewage, 2014: A new locality and host record for Enterogyrus coronatus (Pariselle Lambert \& Euzet (1991) in South Africa and a review of the morphology and distribution of Enterogyrus (Ancyrocephalidae) species. Helminthol.51 , 13-22, DOI: 10.2478/s11687-014-0203-1.

Madanire-Moyo, G.N., and A. Avenant-Oldewage, 2015: The histopathology of Enterogyrus coronatus Pariselle, Lambert \& Euzet, 1991 (Monogenoidea) in the stomach of the southern mouthbrooder Pseudocrenilabrus philander (Weber, 1897) (Cichlidae).African Zool. 50 , 175-180, DOI: 10.1080/15627020.2015.1048729.

Martins, M.L., L. Cardoso, N. Marchiori, and S. Benites de Pádua, 2015: Protozoan infections in farmed fish from Brazil: diagnosis and pathogenesis Infeç̧ões por protozoários em peixes cultivados no Brasil: diagnóstico e patogênese. Braz. J. Vet. Parasitol. 24 , 1-20, DOI: 10.1590/S1984-29612015013. 
Niu, G., R. Khattiya, T. Zhang, S. Boonyayatra, and D. Wongsathein, 2020: Phenotypic and genotypic characterization of Streptococcusspp. isolated from tilapia (Oreochromis spp.) cultured in river-based cage and earthen ponds in Northern Thailand. J. Fish Dis. 43 , 391-398, DOI: 10.1111/jfd.13137.

Nofal, M.I., and H.M.R. Abdel-Latif, 2017: Ectoparasites and bacterial co-infections causing summer mortalities among cultured fishes at Al-Manzala with special reference to water quality parameters.Life Sci. J. 14, 9-15, DOI: 10.7537/marslsj140617.11.Keywords.

Noga, E.J., and J.R. Flowers, 1995: Invasion of Tilapia mossambica ( Cichlidae ) viscera by the Monogenean Enterogyrus cichlidarum. J. Parasitol. 81, 815-817.

Oh, W.T., J.W. Jun, H.J. Kim, S.S. Giri, S. Yun, S.G. Kim, S.W. Kim, J.W. Kang, S.J. Han, J. Kwon, and S.C. Park, 2020: Characterization and pathological analysis of a virulent Edwardsiella anguillarumstrain isolated from Nile tilapia (Oreochromis niloticus) in Korea. Front. Vet. Sci. 7 , 1-8, DOI: 10.3389/fvets.2020.00014.

Pakingking, R., P. Palma, and R. Usero, 2020: Aeromonas load and species composition in tilapia (Oreochromis niloticus ) cultured in earthen ponds in the Philippines. Aquac. Res. 51 , 4736-4747, DOI: 10.1111/are.14820.

Paperna, I., 1963: Enterogyrus cichlidarum n.gen., n.sp., a monogenetic trcmatode parasitic in the intestine of a fish. Bull. Res. Counc. Isr. Sect. B 11, 183-187.

Pariselle, A., and L. Euzet, 2009: Systematic revision of dactylogyridean parasites (Monogenea) from cichlid fishes in Africa, the Levant and Madagascar. Zoosystema 31 , 849-898.

Pariselle, A., A. Lambert, and L. Euzet, 1991: A new type of haptor in mesoparasitic monogeneans of the genus Enterogyrus Paperna, 1963, with a description of Enterogyrus foratus n.sp and E. coronatus n.sp., stomach parasites of Cichlids in West Africa.Syst. Parasitol. 20 , 211-220.

Proietti-Junior, A.A., L.S. Lima, E.M. Roges, Y.C. Rodrigues, K.V.B. Lima, D.P. Rodrigues, and M. TavaresDias, 2021: Experimental co-infection by Aeromonas hydrophila and Aeromonas jandaei in pirarucu Arapaima gigas (Pisces: Arapaimidae). Aquac. Res. are.15021, DOI: 10.1111/are.15021.

Qiagen, 2020: DNeasy (r) Blood \& Tissue Handbook.

Raj, N.S., T.R. Swaminathan, A. Dharmaratnam, S.A. Raja, D. Ramraj, and K.K. Lal, 2019: Aeromonas veronii caused bilateral exophthalmia and mass mortality in cultured Nile tilapia, Oreochromis niloticus (L.) in India. Aquaculture 512, 734278, DOI: 10.1016/j.aquaculture.2019.734278.

Rasmussen-Ivey, C.R., M.J. Hossain, S.E. Odom, J.S. Terhune, W.G. Hemstreet, C.A. Shoemaker, D. Zhang, D.H. Xu, M.J. Griffin, Y.J. Liu, M.J. Figueras, S.R. Santos, J.C. Newton, and M.R. Liles, 2016: Classification of a hypervirulent Aeromonas hydrophila pathotype responsible for epidemic outbreaks in warm-water fishes. Front. Microbiol. 7 , 1-16, DOI: 10.3389/fmicb.2016.01615.

Rodrigues, F.S., I.M. Assane, G.M.R. Valladao, F.G. de Paula, C.L. Andrade, A.P. de Moraes, M. Dall'Agnol, L.M. Pascoal, F.G. de Paula, C.L. Andrade, A.P. de Moraes, M. Dall'Agnol, and L.M. Pascoal, 2019: First report of Trichodinella and new geographical records of trichodinids in Nile tilapia (Oreochromis niloticus ) farmed in Brazil. Rev. Bras. Parasitol. Vet. 28 , 229-237, DOI: 10.1590/s1984-29612019038.

Ronquist, F., and J.P. Huelsenbeck, 2003: MrBayes 3: Bayesian phylogenetic inference under mixed models. Bioinformatics19 , 1572-1574, DOI: 10.1093/bioinformatics/btg180.

Sebastiao, F.A., L.R. Furlan, D.T. Hashimoto, and F. Pilarski, 2015: Identification of bacterial fish pathogens in Brazil by direct colony PCR and 16S rRNA gene sequencing. Adv. Microbiol. 05 , 409-424, DOI: 10.4236/aim.2015.56042.

Sebastiao, F.A., F. Pilarski, M.T. Kearney, and E. Soto, 2017: Molecular detection of Francisella noatunensis subsp . orientalis in cultured Nile tilapia (Oreochromis niloticus L.) in three Brazilian states. J. Fish Dis. 
40 , 1731-1735, DOI: 10.1111/jfd.12636.

Sudheesh, P.S., A. Al-Ghabshi, N. Al-Mazrooei, and S. Al-Habsi, 2012: Comparative pathogenomics of bacteria causing infectious diseases in fish. Int. J. Evol. Biol. 2012 , 1-16, DOI: 10.1155/2012/457264.

Sumithra, T.G., K.J. Reshma, V.N. Anusree, P. Sayooj, S.R.K. Sharma, G. Suja, P. V. Amala, S. Joseph, and N.K. Sanil, 2019: Pathological investigations of Vibrio vulnificus infection in Genetically Improved Farmed Tilapia (Oreochromis niloticus L.) cultured at a floating cage farm of India. Aquaculture 511, DOI: 10.1016/j.aquaculture.2019.734217.

Tavares-dias, M., and M.L. Martins, 2017: An overall estimation of losses caused by diseases in the Brazilian fish farms. J. Parasit. Dis. 41 , 913-918, DOI: 10.1007/s12639-017-0938-y.

Valenti, W.C., H.P. Barros, P. Moraes-Valenti, G.W. Bueno, and R.O. Cavalli, 2021: Aquaculture in Brazil: past, present and future.Aquac. Reports 19 , 100611, DOI: 10.1016/j.aqrep.2021.100611.

Vanhove, M.P.M., P.I. Hablutzel, A. Pariselle, A. Šimková, T. Huyse, and J.A.M. Raeymaekers, 2016: Cichlids: A host of opportunities for evolutionary parasitology. Trends Parasitol. 32 , 820-832, DOI: 10.1016/j.pt.2016.07.002.

Yáñez, M.A., V. Catalán, D. Apráiz, M.J. Figueras, and A.J. Martínez-Murcia, 2003: Phylogenetic analysis of members of the genus Aeromonas based on gyrB gene sequences. Int. J. Syst. Evol. Microbiol. 53 , 875-883, DOI: $10.1099 /$ ijs.0.02443-0.

Zhang, S., T. Zhi, X. Xu, Y. Zheng, C.F. Bilong Bilong, A. Pariselle, and T. Yang, 2019: Monogenean fauna of alien tilapias (Cichlidae) in south China. Parasite 26 , 4, DOI: 10.1051/parasite/2019003.

\section{Tables}

Table 1. Measurements ( $\mu \mathrm{m})$ of Enterogyrus found on Nile tilapia, Oreochromis niloticus (L.), cultured in Brazil. The data are presented as arithmetic mean \pm standard deviation (minimum-maximum). Pe- penis.

\begin{tabular}{lll}
\hline Character & Enterogyrus coronatus & Enterogyrus malmbergi \\
\hline Body length & $107.59 \pm 6.17(99-113.26)$ & $140.22 \pm 19.00(104.95-187.92)$ \\
Body width & $33.32 \pm 2.35(30.09-35.64)$ & $69.98 \pm 12.84(44.75-97.35)$ \\
Pharynx diameter & $31.73 \pm 1.84(29.5-34.02)$ & $64.10 \pm 12.13(45.31-83.65)$ \\
Haptor length & $72.91 \pm 4.27(68.54-78.72)$ & $68.37 \pm 18.46(38.46-105.24)$ \\
Haptor width & $121.82 \pm 7.54(111.84-130.09)$ & $163.14 \pm 30.91(112.30-229.23)$ \\
Pe total curved length & $66.10 \pm 4.52(60.86-71.89)$ & $44.23 \pm 6.35(28.05-51.52)$ \\
Pe base maximum width & $8.53 \pm 0.39(8.02-8.97)$ & $7.14 \pm 0.51(6.24-7.77)$ \\
Dorsal anchor & Dorsal anchor & Dorsal anchor \\
a & $13.58 \pm 0.84(12.08-14.99)$ & $26.49 \pm 1.75(22.54-29.16)$ \\
b & $20.02 \pm 1.31(17.94-22.03)$ & $35.13 \pm 2.01(29.38-38.61)$ \\
c & $17.27 \pm 1.76(14.74-18.98)$ & $25.82 \pm 1.97(20.41-30.04)$ \\
d & $10.7 \pm 0.48(10.19-11.6)$ & $18.05 \pm 1.69(14.64-23.13)$ \\
e & $5.12 \pm 1.03(3.37-6.74)$ & $6.85 \pm 1.01(4.61-8.60)$ \\
Ventral anchor & Ventral anchor & Ventral anchor \\
a & $14.55 \pm 0.01(14.53-14.57)$ & $20.94 \pm 1.42(17.38-23.46)$ \\
b & $12.2 \pm 0.37(11.83-12.57)$ & $14.49 \pm 1.44(9.87-16.47)$ \\
c & $6.07 \pm 0.12(5.95-6.2)$ & $8.91 \pm 2.23(4.95-13.35)$ \\
d & $5.44 \pm 0.13(5.31-5.57)$ & $11.71 \pm 1.73(7.11-16.32)$ \\
e & $4.51 \pm 0.33(4.17-4.85)$ & $5.99 \pm 1.99(2.38-12.49)$ \\
Ventral bar length & $6.25 \pm 0.16(6.01-6.38)$ & $23.21 \pm 3.44(14.35-27.7)$ \\
Ventral bar width & $0.87 \pm 0.13(0.77-1.07)$ & $5.43 \pm 1.02(2.83-7.42)$ \\
Hooks & Hooks & Hooks
\end{tabular}




\begin{tabular}{lll}
\hline Character & Enterogyrus coronatus & Enterogyrus malmbergi \\
\hline I & $14.24 \pm 0.06(14.17-14.30)$ & $13.76 \pm 1.23(9.74-15.12)$ \\
II & - & $13.29 \pm 1.11(11.08-14.91)$ \\
III & $12.07 \pm 1.27(10.29-13.17)$ & $13.67 \pm 1.41(10.33-15.38)$ \\
IV & $12.88 \pm 1.05(11.27-14.34)$ & $14.28 \pm 1.26(11.22-15.92)$ \\
V & $10.95 \pm 1.00(9.40-12.60)$ & $14.12 \pm 1.46(10.59-16.37)$ \\
VI & $12.61 \pm 0.60(11.61-13.17)$ & $14.49 \pm 1.46(10.86-16.5)$ \\
VII & $13.13 \pm 1.99(9.94-15.26)$ & $1.62(10.41-16.51)$ \\
\hline
\end{tabular}

\section{Figure Legends}

Figure 1. Clinical signs of Nile tilapia cultured in Brazil experiencing high mortality after transport stress. The clinical signs, including cloudy eye (southeast arrow), fin erosion (northwest arrow), sloughing of scales (asterisk), haemorrhages on the skin and internal organs (leftwards thick arrow), and enlarged and pale liver were attributed to the co-infection by Enterogyrus spp. (Monogenea: Ancyrocephalinae) and Aeromonas jandaei.

Figure 2. Scanning electron micrographs of Enterogyrusin the stomach of Nile tilapia cultured in Brazil. A. the interior surface of the stomach (s), showing specimen (downwards thick arrow), the parasite-induced lesion (rightwards thick arrow from wall), B. specimen mouth (northwest thick arrow) and tegumental surface, showing transverse folds (star). C. a pit created by the attachment of specimen (southeast thick arrow). Evidence of prior attachment by anchors (asterisk) of Enterogyrus (D, E, F, G). Note that pits are filled with blood cells (leftwards triple dash arrow) and bacteria (leftwards arrow with plus below). phprohaptor.

Figure 3. Morphology of Enterogyrus coronatus andE. malbergi recovered from the stomachs of Nile tilapia cultured in Brazil. A. body shape of E. coronatus ; B. high magnification of the haptor (h), showing the arrangement of dorsal (da) and ventral (va) anchors, and marginal hooks (mh). C. high magnification of penis (pe). D. high magnification of prohaptor (ph), showing details of the mouth $(\mathrm{m})$ and pharynx $(\mathrm{p})$. E. body shape of E. malbergi . F. high magnification of the haptor showing the arrangement of dorsal and ventral anchors, marginal hooks, and ventral bar (vb). G. high magnification of penis. H. high magnification of prohaptor, showing details of the mouth and pharynx. es- eyespots. Scale bar $10 \mu \mathrm{m}$.

Figure 4. Scanning electron micrographs of Enterogyrus foratus -like specimen (A), E. malbergi (B) and $E$. coronatus (C) recovered from the stomachs of Nile tilapia cultured in Brazil showing their morphology. High magnification of haptor of Enterogyrus spp. (D), E. malbergi (E), and E. coronatus (F). High magnification of anchors of Enterogyrus spp. (G. lateral view, H. dorsal view), E. malbergi (E), and E. coronatus (F) showing the morphology of the sclerotized parts. Downwards thick arrow indicates the limit between the specimen tegumental surface with transverse folds visible (star) and covered with mucus (asterisk), suggesting a deep penetration of parasite into host tissue. a. anchor; da. dorsal anchor; va. ventral anchor; h. haptor; $\mathrm{m}$. mouth; mh. marginal hooks; p. pharynx; ph. prohaptor. Note that the surface of the hook is smooth.

Figure 5. Rooted phylogenetic tree inferred by Maximum Likelihood (ML) and Bayesian Inference (BI) methods based on multilocus (16S rRNA-gyrB -rpoB ) sequence analysis of two clinical isolates from this study (bold) and 26 recognized Aeromonasisolates from different sources. Plesiomonas shigelloides $\mathrm{NCTC} 10360^{\mathrm{T}}$ and Vibrio anguillarum $\mathrm{NCTC} 12159^{\mathrm{T}}$ were used as outgroups. Support values at the nodes are for ML bootstrap values ([?]70\%)/BI posterior probabilities ([?]0.70) (BP/PP). Type strains of different species are indicated with $^{\mathbf{T}}$.

Figure 6. Hematoxylin-eosin staining of stomach tissue of Nile tilapia parasitized with Enterogyrus spp.. Multiple sections of the trematode helminth (asterisk) can be seen in the lumen: their anterior regions are embedded in damaged mucosa, which is extensively ulcerated (arrows). The damaged tissue did not show 
any inflammatory reaction and gland alterations. The ulcers at the epithelial layer (Ep) do not reach the submucosa $(\mathrm{Sm})$ and muscularis mucosa $(\mathrm{Mm})$.
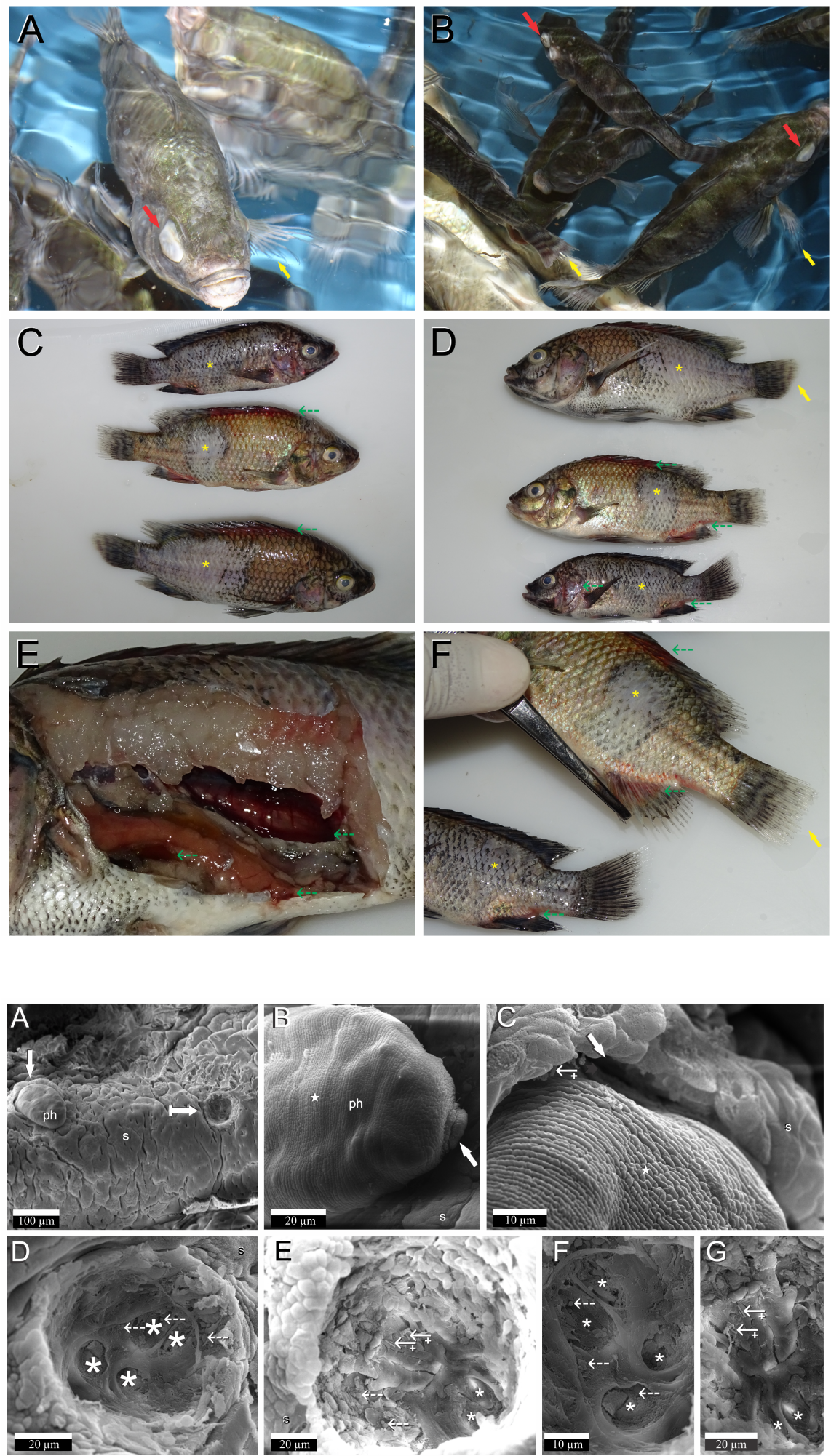

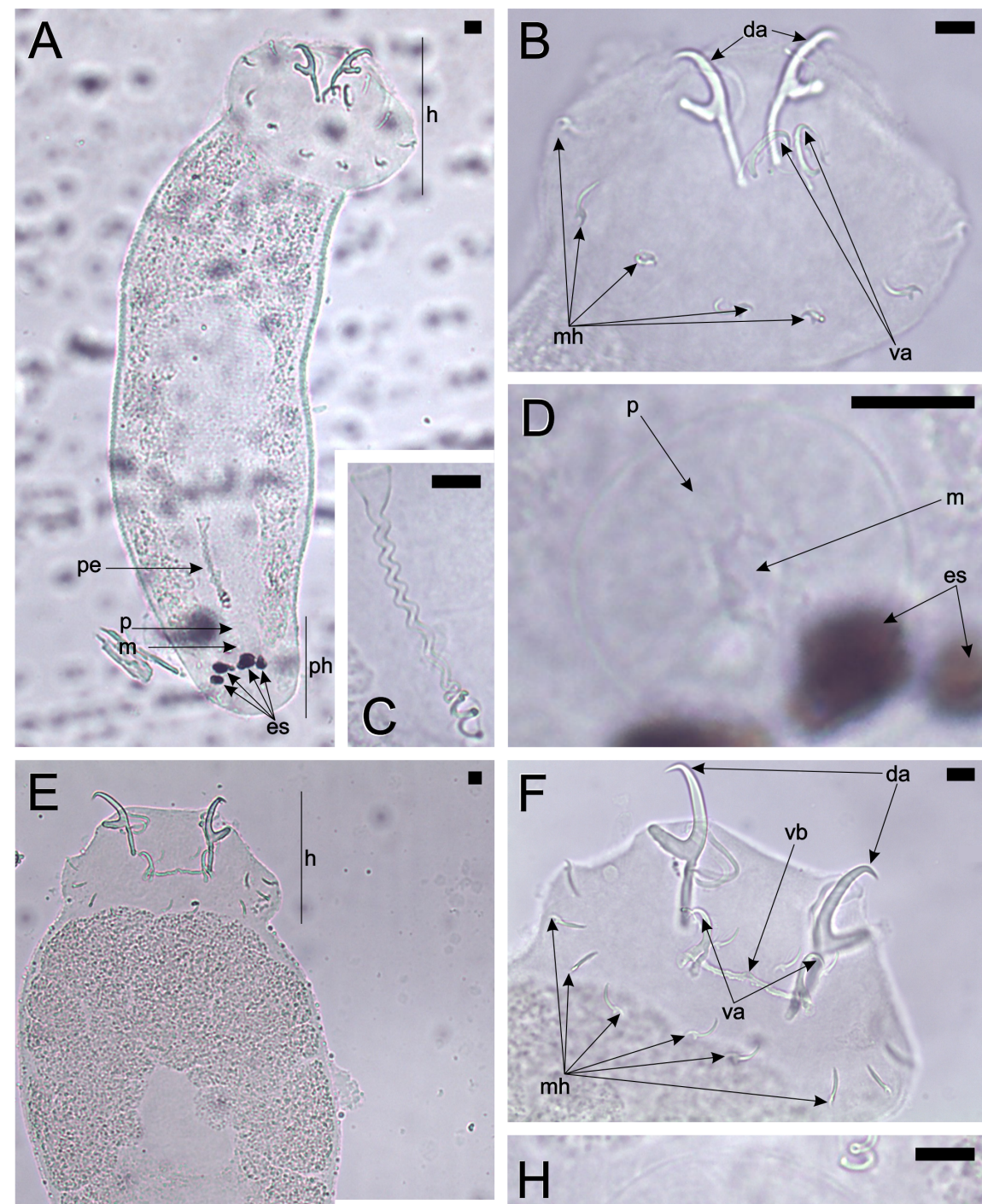

$F$
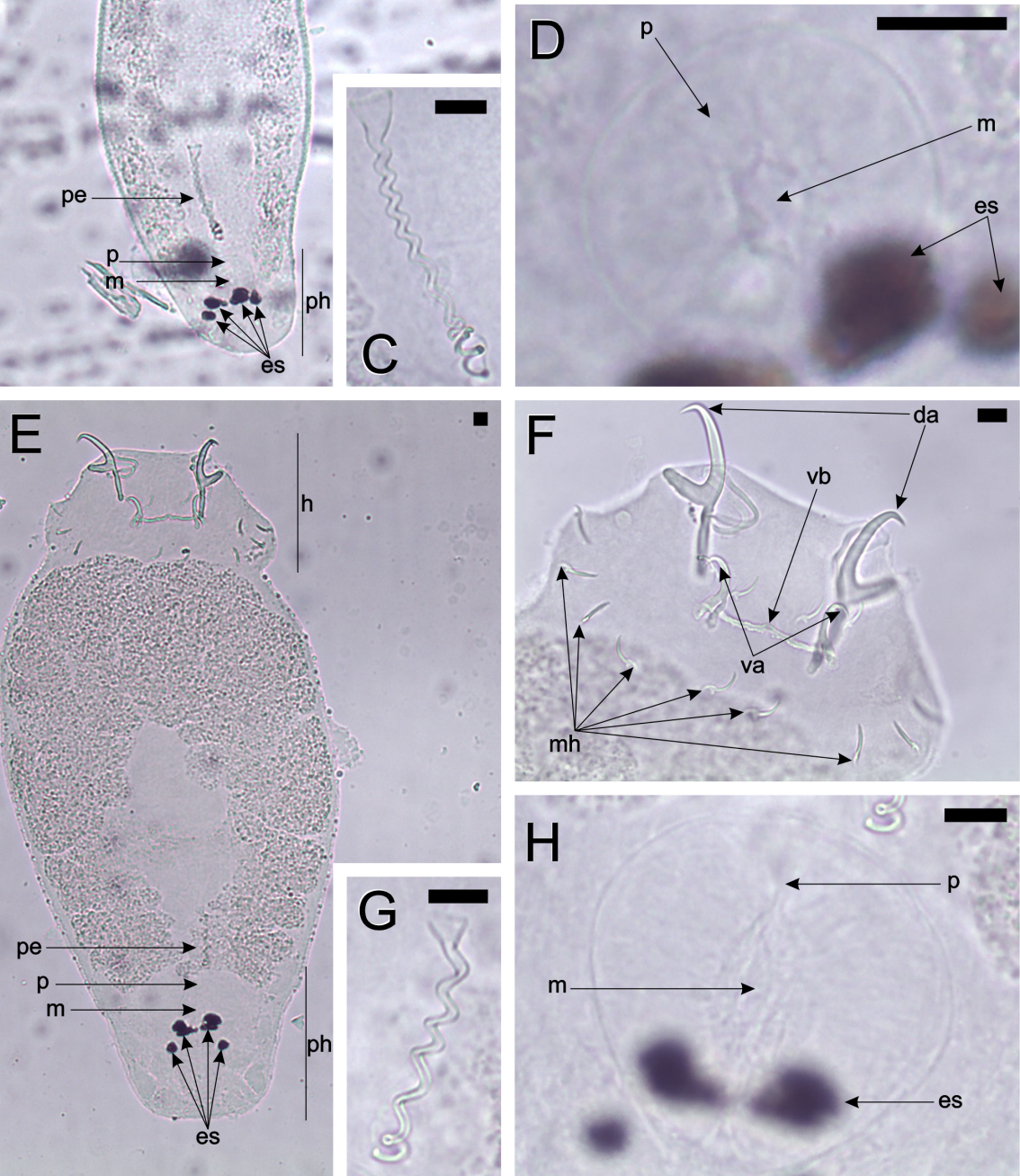

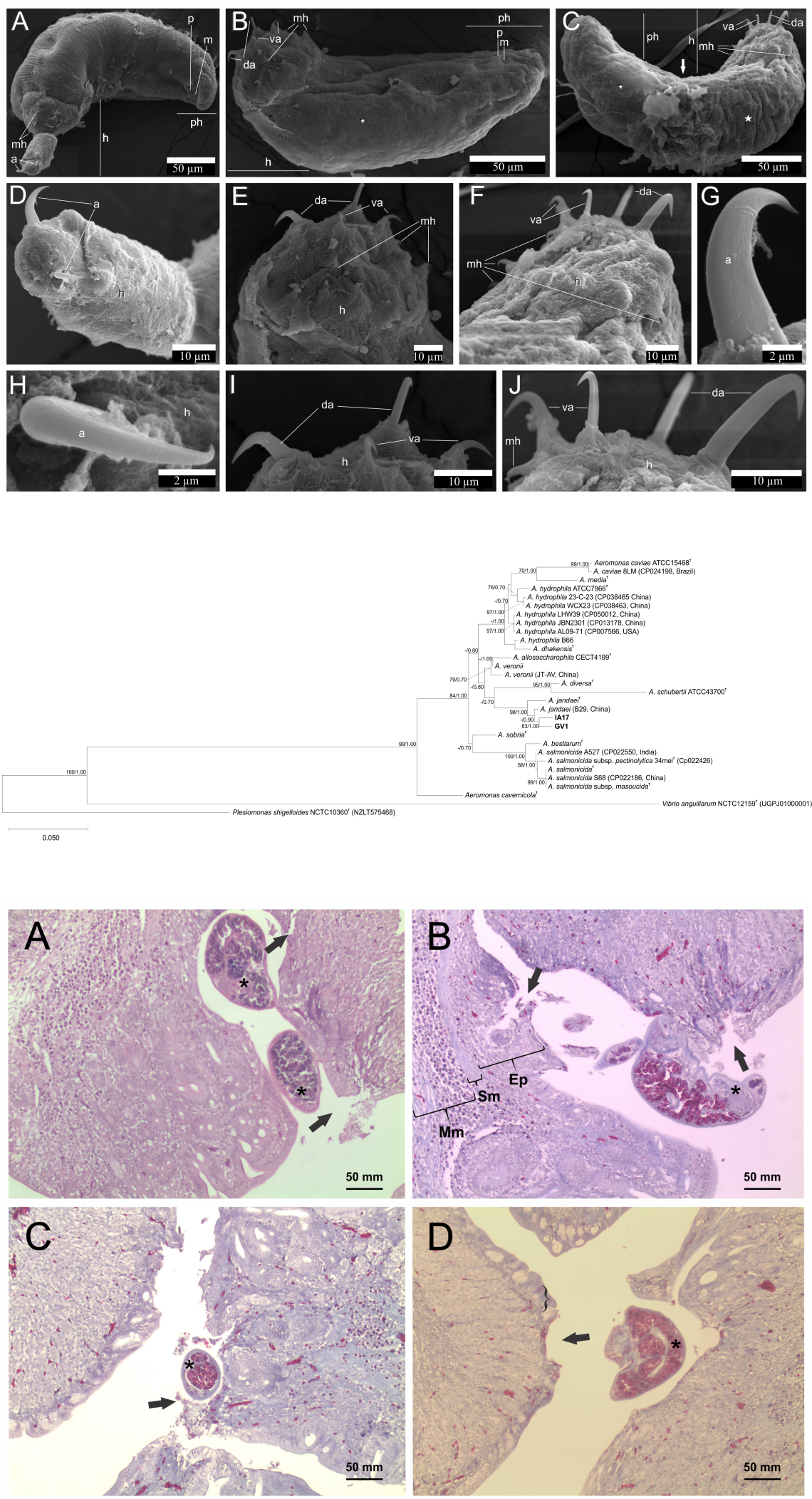